\title{
PERAN KOMITMEN ORGANISASIONAL DALAM MEMEDIASI PENGARUH STRES KERJA TERHADAP TURNOVER INTENTION DI BALI ROCHMAT JAYA
}

\author{
I Gede Yudika Putra ${ }^{1}$ \\ I Komang Ardana ${ }^{2}$
${ }^{1,2}$ Fakultas Ekonomi dan Bisnis Universitas Udayana, Bali, Indonesia Email: gedeyudhikaputra16@gmail.com

\begin{abstract}
ABSTRAK
Turnover intention adalah salah satu bentuk prilaku menarik diri didalam dunia kerja, akan tapi sekaligus juga yaitu hak bagi setiap individu untuk menentukan pilihannya perusahaan tersebut. Turnover merupakan masalah serius di bidang Manajemen Sumber Daya Manusia yang berkaitan dengan perputaran tenaga kerja yang tinggi. Penelitian ini bertujuan untuk mengetahui peran komitmen organisasional dalam memediasi pengaruh stres kerja terhadap turnover intention. Penelitian ini dilakukan pada PT Bali Rochmat Jaya, sampel ditentukan menggunakan metode sensus dan didapatkan sampel sejumlah 40 orang pegawai. Pengumpulan data menggunakan kuesioner. Teknik analisis yang digunakan adalah analisis faktor dan path analysis untuk menguji pengaruh stress kerja dan komitmen organisasional terhadap turnover intention. Hasil yang ditemukan pertama stress kerja berpengaruh negatif terhadap komitmen organisasional. Kedua menunjukan stress kerja berpengaruh positif terhadap turnover intention. Ketiga menunjukan komitmen organisasioanl berpengaruh negatif terhadap turnover intention, dan yang terakhir hipotesis komitmen organisasional memediasi secara signifikan hubungan antara stress kerja terhadap turnover intention.
\end{abstract}

Kata kunci : stress kerja, komitmen organisasional, turnover intention.

\begin{abstract}
Turnover intention is one form of behavior withdrawal in the world of work, but it is also a right for every individual to determine his choice company. This study is aims to determine the role of organizational commitment in mediating the influence of work stress on turnover intention. This research was conducted at PT Bali Rochmat Jaya, Bali, the sample was determined using census method and got a sample of 40 employees. Data collection using questionnaires. The analysis technique used is factor analysis and path analysis to test the effect of work stress and organizational commitment to turnover intention. The results of the first work stress have a negative effect on organizational commitment. Both of them show work stress positively influence to turnover intention. The third shows organizational commitment negatively affecting turnover intention, and finally the hypothesis of organizational commitment mediates significantly the relationship between work stress on turnover intention.
\end{abstract}

Keyword : job stress, organizational commitment, turnover intention. 
I Gede Yudika Putra, Peran Komitmen Organisasional...

\section{PENDAHULUAN}

Bersaing didalam dunia bisnis pada era globalisasi yang makin ketat, jadi organisasi haruslah bisa mempunyai sebuah kelebihan serta keahlian berdaya saing yang besar, supaya bisa berlanjut juga bersaing dengan organisasi lain. Supaya bisa mempunyai kelebihan serta berdaya saing yang besar dibutuhkan sumber daya yang baik. Pengolahan Sumber Daya Manusia (SDM) haruslah bisa berjalan dengan bagus supaya organisasi bisa melakukan persaingan dengan organisasi-organisasi lain. Turnover intention adalah salah satu bentuk prilaku menjauhkan diri didalam dunia pekerjaan, tapi juga termasuk didalam hak bagi seluruh pegawai agar membuat penentuan pilihan, apa terus bekerja ataupun keluar dari organisasi itu. Turnover adalah masalah serius pada bidang Manajemen SDM yang berhubungan dengan rotasi pekerja yang besar (Kumar et al., 2012). Turnover yang besar sangat bahaya bagi organisasi serta hal itu punla membuat pengurangan efisien juga produktivitas perusahaan. Efek jelek dari besarnya tingkat turnover pegawai pula bisa membuat terjadinya pembengkakan beban yang lumayan tinggi dikarenakan organisasi lainnya haruslah membuat suatu investasi beban dalam melaksanakan rekrutmen, orientasi, pelatihan, lembur, serta pengawasan (Suryani, 2011).

Sianipar dan Haryati (2014) memberi penjelasan bagaimana tandanya jika pegawai ingin melaksanakan turnover intention yaitu absensi yang terus mengalami peningkatan, mulai malas untuk kerja, meningkatnya pelanggaran pada tata tertib kerja pegawai, peningkatan protes pada atasan serta prilaku positif yang cukup membedakan dari biasanya. Berdasar tanda-tanda pegawai 
melaksanakan turnover intention itu pun telah ada pada karyawan di PT. Bali Rochmat Jaya. Terlihat dari karyawan yang mulai malas untuk menyebar brosur, karyawan sering absen. Permasalahan tersebut dapat mengindikasikan terjadinya turnover intention di PT. Bali Rochmat Jaya. Turnover intention karyawan dari suatu perusahaan bisa dikarenakan oleh sekian variabel diantaranya stres kerja, beban kerja dan lingkungan non fisik (Qureshi et al., 2012).

Stres adalah suatu kondisi ketegangan yang mempengaruhi emosi, proses berfikir dan kondisi seseorang. Stres adalah bidang perhatian bagi pengusaha serta pegawai sebagai bagian dari perusahaan, stres memberi penentuan optimal ataupun tidaknya output pegawai serta membikin kerja pegawai itu memberi arti untuk mereka. Stres di tempat kerja akhir-akhir ini telah menjadi masalah yang serius bagi manajemen perusahaan di dalam dunia bisnis (Hlatywayo et al., 2014). Disamping stress kerja, komitmen organisasional adalah sebuah dari sekian faktor yang banyak orang percaya mempunyai peran banyak pada hasil yang didapatkan organisasi, termasuk kinerja didalam dan diluar organisasi, juga keinginan serta prilaku turnover intention. Komitmen organisasional bisa dibagi menjadi tiga pendekatan, adalah afektif, keberlanjutan serta komitmen. Komitmen adalah kondisi psikologic yang menampilkan hubungan diantara pegawai dan organisasi juga mempunyai implikasi pada keputusan pegawai agar tetap bertahan ataupun keluar dari perusahaan.

Komitmen organisasional yang besar tentunya akan senang ada didalam perusahaan. Salah satu bentuk komitmen yang diperlihatkan pegawai yaitu kinerja yang bertambah, sedikitnya tingkat absensi serta rasa ingin agar tak mencari 
I Gede Yudika Putra, Peran Komitmen Organisasional...

alternatif kerjaan lainnya. Bila komitmen organisasional sedikit, jadi tingkat kesetiaan pegawai pada organisasi pun akan sedikit juga membuat peningkatan rasa ingin pegawai agar tak bertahan menjadi anggota didalam organisasi Novriyadhi dan Gede (2015).

Berdasarkan hasil observasi yang dilakukan pada karyawan yang bekerja pada PT. Bali Rochmat Jaya, memang benar terdapat beberapa masalah yang dialami oleh para karyawan dalam menjalani pekerjaanya, permasalahan tersebut biasanya dikarenakan kurang baiknya komunikasi antara karyawan, sehingga akan menyebabkan konflik antara karyawan yang menyebabkan karyawan merasakan stres, dan bedasarkan hasil wawancara kepada manajer PT. Bali Rochmat Jaya menyatakan bahwa masih adanya karyawan yang bermalas - malasan pada saat bekerja, kurang giatnya para marketing untuk menyebarkan brosur. PT. Bali Rochmat Jaya merupakan anak perusahaan dari Graha Agung Kencana yang berlokasi di Surabaya, sedangkan PT Bali Rochmat jaya berlokasi di Tabanan. PT. Bali Rochmat Jaya berdiri pada tahun 2009 dan bergerak di bidang properti. Dari data observasi awal menunjukan jumlah karyawan pada PT. Bali Rochmat Jaya yang berjumlah 40 orang. Diantaranya terdiri dari Direktur 1 orang, Manajer Marketing 1 orang, Marketing 10 orang, Accounting 2 orang, Kasir 2 orang, Admin 2 orang, Pengawas Lapangan 3 orang, Bagian Umum 2 orang, Satpam 3 orang, Cleaning Service 2 orang, Sopir 1 orang, Kepala Produksi 1 orang dan Bagian Produksi 10 Orang.

Rumusan masalah dalam penelitian ini adalah sebagai berikut. 1) Bagaimana pengaruh stres kerja terhadap komitmen organisasional ? 2) 
Bagaimana pengaruh stres kerja terhadap turnover intention? 3) Bagaimana pengaruh komitmen organisasional terhadap turnover intention? 4) Bagaimana peran komitmmen organisassional didalam pemediasi stress kerja pada turnover intention? Tujuan yang ingin diketahui dalam penelitian ini adalah sebagai berikut. 1) Untuk menganalisis pengaruh stres kerja terhadap komitmen organisasional. 2) Untuk menganalisis pengaruh stres kerja terhadap turnover intention. 3) Untuk menganalisis pengaruh komitmen organisasional terhadap turnover intention. 4) Untuk menjelaskan peran komitmmen organisasional didalam pemediasi stress kerja pada turnover intention. Hasil penelitian ini diharapkan dapat menjadi sumber informasi di bidang ilmu manajemen sumber daya manusia, khususnya dalam aspek stres kerja, komitmen organisasional dan turnover intention. Hasil Penelitian ini diharapkan dapat memberi masukan kepada manajer dalam menangani masalah seperti stres kerja, komitmen organisasional dan turnover intentionyang terjadi di dalam perusahaan.

Teori yang yang melandasi penelitian ini adalah Teori Pertukaran Sosial (Social Exchange Theory) yang menjelaskan berbagai transaksi yang terjadi di seluruh kehidupan sosial seseorang yang ditandai dengan hubungan emosional yang kuat. Teori mengenai struktur sosial itu berdasar bahwasannya macam prilaku sosial yang terjadi tersebut ditimbulkan oleh suatu harapan dimana tindakan seorang didalam hubungannya dengan orang lain dapat memberi akibat timbulnya hubungan timbal balik yang sama (Rebel dalam Dockel, 2006). Kemudian Meyer dan Herscovith (2001) menyatakan bahwa apabila faktor faktor keterlibatan emosional, keterikatan, keyakinan dan kesediaan kita pandang 
I Gede Yudika Putra, Peran Komitmen Organisasional...

genting didalam proses perkembangan komitmen organisasional, jadi diperlukan adanya usaha membuat perbedaan mindset itu hingga ada relevansi tindakan serta usahan pada tujuan yang dibuatkan rumus dan dengan adanya relevansi tindakan tersebut dapat membuat perbedaan komitmen afektif, komitmen kontinuan juga komitmen normatif diantara satu dan yang lain.

Meyer dan Hersovitch (2001) memberi penjelasan beda dari tiga komitmen itu sebagaimana: 1) Mindset of desire (affective commitment) mengalami perkembangan saat individu mempunyai keterlibatan, kenal akan nilai - nilai ataupun mencurahkan diri kedalam suatu entitas, kelompok ataupun perusahaan. 2) Mindset of perceived cost (continuance commitment) mengalami perkembangan saat seseorang kenal bahwasannya yang rugi ataupun merasaka tak adanya alternatif lainnya kecuali melaksanakan jenis kerja seperti sekarang. 3) Mindset of obligation (normative commitment) mengalami perkembangan saat hasil internalisasi nilai-nilai melewati sosialisasi, penerimaan rasa untung juga kontrak psikologis yang telah tetap bisa dilakukan kesepakatan ataupun memiliki rasa.

Adenguga et al. (2013) dalam Setiawan (2016) memberi pernyataan variabel turnover intention memiliki tiga indikasi yang akan menjadi sebuah dasar didalam menilai rasa ingin agar keluar itu, adalah: 1) timbulnya rasa ingin keluar dari organisasin 2) timbulnya rasa ingin dalam melakukan pencarian kerjaan lainnya 3) rasa ingin dalam keluar dari organisasi didalam sekian bulan berikutnya. Meyer dan Allen (1991) membagi komitmen organisasional ke dalam 3 dimensi yaitu komitmen afektif (affective commitment), komitmen normatif 
(normative commitment), dan komitmen berkelanjutan (continuance commitment). Indikator dalam pengukuran stres kerja ini diantaranya adalah tuntutan tugas, tuntutan peran, tuntutan hubungan antar pribadi, struktur organisasi, kepemimpinan organisasi dan tahap hidup organisasi.

Kerangka konseptual dalam penelitian ini dapat dijelaskan melalui Gambar 1 Secara ringkas kerangka konseptual penelitian ini menjelaskan tentang peran komitmen organisassional didalam memediasi pengaruh stres kerja pada turnover intention sebagai berikut.

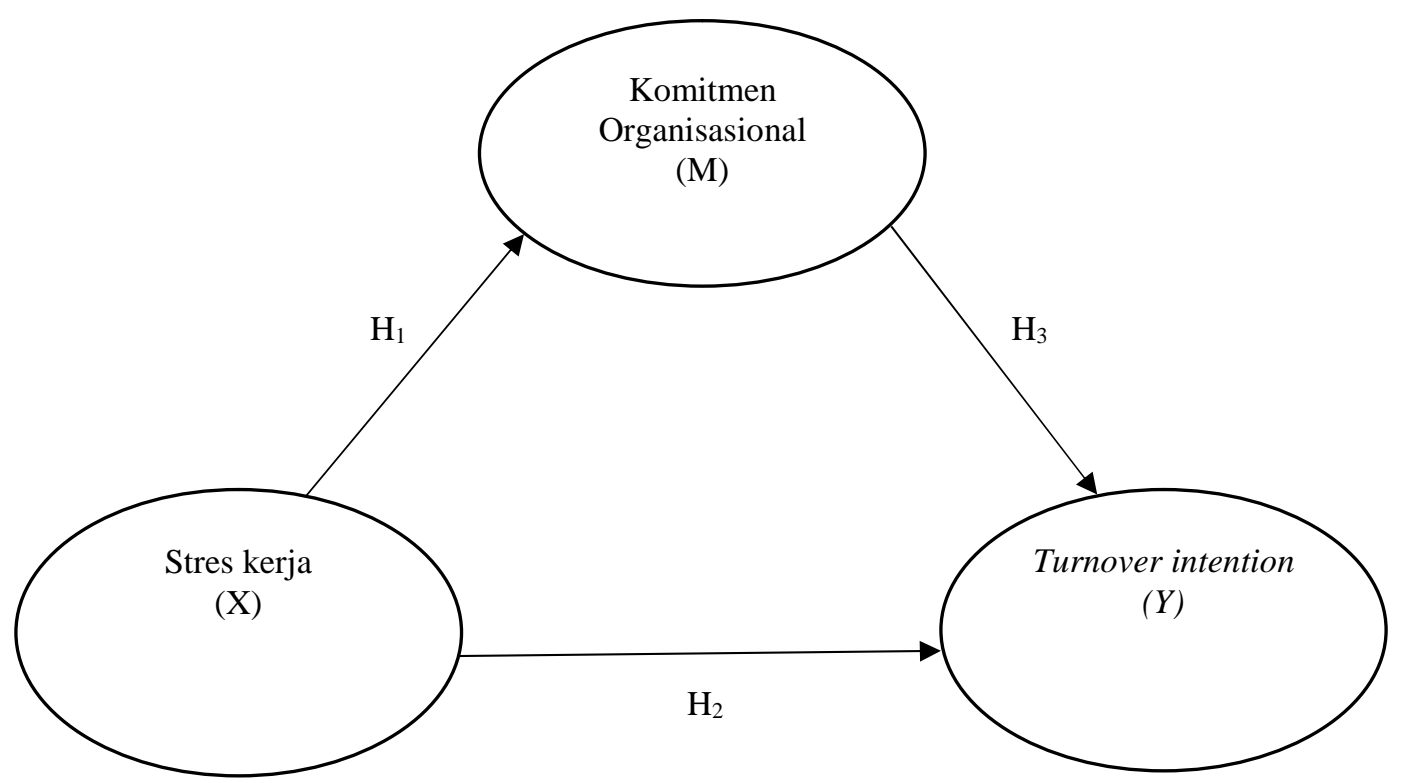

Gambar 1. Kerangka Konseptual

Sumber: Data Diolah, 2017

Khatibi et al. (2009) serta Firth et al. (2004) meyatakan terdapat hubungan negatif diantara stress kerja dengan komitmen organiasional, pegawai yang mempunyai tingkat stress tinggi memiliki implikasi pada rendah tidaknya komitmen organisasionalnya. Velnampy juga Aravinthan (2013) memberi pernyataan adanya hubungan negatif diantara stress kerja serta komitmen organisasional. Cha et al. (2011) mengungkapkan stress kerja mempunyai 
I Gede Yudika Putra, Peran Komitmen Organisasional...

hubungan yang negatif dengan komitmen organisasional. Perannya konflik serta peran ambigius bagai pembuat stress memiliki hubungan pada turunnya komitmmen organisasi yang berarti adanya hubungan yang negatif serta signifikan diantara stress kerja dengan komitmen organisasional (Pool, 2000).

$\mathrm{H}_{1}$ : Stres kerja berpengaruh negatif terhadap komitmen organisasional.

Hermitha (2011), mengidentifikasi 5 jenis konsekuensi dampak stres yang potensial, salah satunya berdampak jelas pada organisasi adalah keabsenan, pergantian karyawan (turnover) yang tinggi, rendahnya produktivitas, keterasingan dari rekan kerja ketidakpuasan kerja, menurunnya keterikatan dan kesetiaan terhadap organisasi. Penelitian yang dilaksanakan oleh Klassen (2011) mengungkapkan bahwasannya stress kerja mempunyai pengaruh positif pada keinginan pegawai untuk keluar, pegawai yang mengalami stress kerja yang berlebihan berimplikasi pada turnover intention. Penelitian Parvaiz et al. (2015) pun memberi petunjuk stress kerja mempunyai hubungan positif dengan turnover intention, bila pegawai mengalami stress kerja serta tak mempunyai mekanisme yang sesuai agar mengurangi stress kerja itu, jadi dapat menimbulkan rasa ingin pegawai meninggalkan perusahaan.

Layne et al. (2004), menyatakan adanya hubungan positif diantara stress kerja dengan turnover intention, makin tingginya tingkat stress yang dimiliki seorang pegawai dapat sekiranya berpengaruh terhadap peningkatan rasa ingin karyawan resign dari perusahaan. Penelitian yang dilaksanakan oleh Mitchell et al. (2014), memberikan pernyataan stress kerja adalah sebab utama timbulnya turnover intention bagi pegawai. 
$\mathrm{H}_{2}$ : Stres kerja berpengaruh positif terhadap turnover intention.

Ahmed et al. (2013) menyatakan bahwa komitmen organisasional berpengaruh negatif signifikan terhadap turnover intention. Hal ini sesuai dengan hasil penelitian Saqib (2014) bahwa komitmen organisasional yang tinggi akan mengakibatkan menurunnya turnover intention karyawan. Pegawai yang memiliki komitmen untuk perusahaannya, memiliki kepercayaan bahwasannya mereka tak akan mendapatkan pekerjaan lain yang lebih bagus serta menunjuk agar tetap di perusahaan (Aydogdu, 2011). Wan et al. (2010) menyebutkan bahwa karyawan yang memiliki komitmen organisasi yang timggi memiliki keinginan untuk pindah yang lebih rendah. Handaru dan Muna (2012), menyatakan bahwasannya komitmen organisasi mempunyai hubungan yang negatif pada turnover intention. Berdasar kepada hasil kajian empiris ataupun penelitian sebelumnya, jadi bisa dirumuskan hipotesis seperti.

$\mathrm{H}_{3}$ : Komitmen organisasional berpengaruh negatif terhadap turnover intention.

Dalam penelitiannya, Firth et al. (2004) memberi pengungkapan komitmen organisasional adalah yang memediasi variable stress kerja serta variabel turnover intention. Akehurst (2009), menyatakan bahwa komitmen organisasional memediasi stres kerja pada turnover intention. Berdasar Anatan dan Ellitan (2007) stress kerja pegawai bisa memberikan peningkatan turnover intention. Stress kerja yang besar bisa memiliki dampak untuk seseorang serta perusahaan, dimana setiap seseorang mengenai stress kerja dapat mempunyai pandangan yang beda. Irwanto dkk. (2016) menyatakan bahwa komitmen organisasional adalah yang memediasi diantara stress kerja terhadap turnover intention. 
I Gede Yudika Putra, Peran Komitmen Organisasional...

$\mathrm{H}_{4}$ : Komitmen organisasional mampu memediasi pengaruh antara stres kerja dan Turnover Intention.

\section{METODE PENELITIAN}

Berdasar kepada masalah yang diteliti, penelitian berikut tergolong kedalam penelitian asosiatif (hubungan), merupakan penelitian yang memiliki tujuan agar tahu pengaruh dari satu variabel, dua variabel ataupun lebih (Sugiyono, 2013:5). Metode ini dipakai agar diketahuinya hubungan diantara variabel stress kerja, komitmen organisassional serta turnover intention. Lokasi penelitian dilaksanakan di PT. Bali Rochmat Jaya yang memiliki alamat di Jalan By. Pass Ir. Soekarno Kediri - Pesiapan, Tabanan. Objek penelitian berikut adalah stress kerja, komitmen organisasional serta turnover intention. Subjek penelitian berikut yaitu seluruh karyawan PT. Bali Rochmat Jaya.

Variabel-variabel yang teridentifikasi didalam penelitian berikut bisa dibagi kedalam dua jenis, adalah: 1) Variabel eksogen (exogenous variabel) merupakan source variable atau independent variable yang tidak diprediksi oleh variabel yang lain dalam model (Hair et al., 2010:580). Variabel eksogen dari penelitian ini adalah Stress Kerja (X). 2) Variabel endogen (endogenous variable) outcome variable atau dependent variable dari paling sedikit satu hubungan kausalitas dalam model (Hair et al., 2010:580). Variabel endogen dalam penelitian ini adalah Turnover Intention (Y). 3) Variabel Endogen Mediasi (M), merupakan variabel yang menghubungkan hubungan antara dua variabel. Variabel endogen mediasi dalam penelitian ini adalah Komitmen Organisasional (M).

Menurut Singarimbun dan Efendi (2003: 46) definisi operasional adalah unsur penelitian yang memberitahukan bagaimana cara mengukur suatu variabel, 
dengan kata lain definisi operasional adalah petunjuk pelaksanaan bagaimana caranya mengukur suatu variabel. Definisi operasional dari setiap variabel penelitian. Turnover intention adalah sebuah gerakan pegawai ingin keluar dari perusahaan yang dilaksanakan dengan sadar agar mencari sebuah kerjaan lain sebagai alternatif di perusahaan lainnya. Adenguga et al. (2013) (dalam Setiawan, 2016) memberi pernyataan variabel turnover intention memiliki tiga indikator yang menjadi dasar dalam pengukuran rasa ingin keluar itu, adalah: 1) timbulnya rasa ingin keluar dari organisasi, 2) timbulnya rasa ingin dalam melakukan pencarian kerjaan lainnya, yaitu rasa ingin dalam melakukan pencarian kerjaan lainnya bisa terjadi apabila organisasi tak bisa mengabulkan kebutuhan pegawai hingga pegawai dapat cendrung agar berfikir menemukan alternatif kerjaan di organisasi lainnya. 3) rasa ingin dalam keluar dari organisasi didalam beberapa bulan kedepan, yaitu pegawai dapat menambah motivasi dalam pencarian kerjaan lainnya di organisasi yang berbeda didalam sekian bulan kedepan yang kita anggap dapat juga bisa mencukupi keperluan hidupnya.

Tiga dimensi komitmen didalam berorganisasi dari Meyer dan Allen (1991) yang dapat menjadi indikator adalah seperti berikut: 1) Affective Commitment adalah terlibat dalam emosional individu untuk perusahaannya berupa perasan cinta pada perusahaan. 2) Continuance Commitment adalah persepsi individu terhadap beban serta resiko bila keluar dari perusahaan pada waktu ini. 3) Normative Commitment adalah suatu dimensi moral yang berdasar kepada adanya kewajiban juga tanggung jawab untuk perusahaan yang menjadikan individu itu pegawainya. Terdapat 3 indikator yang digunakan untuk mengukur tingkat stres 
I Gede Yudika Putra, Peran Komitmen Organisasional...

kerja pada setiap para pekerja yaitu (Alves et al., 2004) : 1) Tuntutan (Demands) adalah suatu persepsi untuk berusaha atau berdaya dalam mencapai suatu tujuan. 2) Kontrol (Control) adalah sebagai proses kegiatan monitoring untuk meyakinkan bahwa semua kegiatan organisasi terlaksana seperti yang direncanakan. 3) Dukungan (Support) adalah dukungan sosial sebagai sumber emosional, informasional atau pendampingan.

Populasi dalam penelitian ini adalah seluruh karyawan PT. Bali Rochmat Jaya. Anggota populasi penelitian ini sejumlah 40 orang. Seluruh anggota populasi dijadian sebagai responden yang berjumlah 40 orang. Metode pengumpulan data dalam penelitian ini menggunakan tiga metode penelitian dalam mengumpulkan data, yaitu: Metode observasi yaitu metode pengumpulan data dengan mengadakan pengamatan secara langsung ke PT. Bali Rochmat Jaya tentang objek yang diteliti. Metode wawancara adalah metode mengumpulkan data melalui cara tanya jawab masalah yang dapat dilakukan penelitian. Pertanyaan yang ditanyakan berkisar antara masalah tentang stress kerja, komitmen organisasional juga turnover intention pegawai PT. Bali Rochmat Jaya. Metode Kuesioner merupakan metode mengumpulkan data dengan memakai daftar pernyataan yang disebar pada responden tentang stress kerja, komitmen organisasional serta turnover intention pegawai PT. Bali Rochmat Jaya.

Sumber data penelitian ini adalah penarikan data primer yang menggunakan kuesioner, maka data yang diperoleh bersifat kualitatif. Skala pengukuran yang digunakan dalam penelitian ini adalah skala Likert. Skala Likert yaitu skala yang digunakan untuk mengukur sikap, pendapat, dan persepsi seseorang atau 
sekelompok orang tentang fenomena sosial. Setiap jawaban kuesioner mempunyai bobot atau skor nilai dengan skala Likert. Responden mengisi sendiri angket yang diberikan tanpa intervensi dari peneliti, namun terlebih dahulu diberikan penjelasan yang cukup, terutama kalau tidak ada kejelasan, atau ketidak selarasan jawaban dibandingkan dengan konsep teori yang mendasarinya.

Data kualitatif didalam penelitian berikut adalah pendapat dari responden yang termasuk variabel stres kerja, komitmen organisasional, turnover intention. Data kuantitatif dalam penelitian ini yaitu data karyawan pada PT. Bali Rochmat Jaya. Sumber primer dalam penelitian ini adalah responden yang langsung memberikan jawaban atau skor terhadap variabel-variabel penelitian yang terdapat dalam kuisioner. Sumber sekunder dalam penelitian ini adalah data yang didapatkan dari sumber-sumber yang telah ada contohnya berasal pada data organisasi, sejarah perusahaan. Instrumen pertanyaan dalam kuesioner dikatakan valid apabila koefisien korelasi $\geq 0,03$. Uji validitas bertujuan untuk memeriksa apakah kuisioner sebagai instrument penelitian sudah tepat untuk mengukur indikator dalam penelitian. Kuesioner dapat dikatakan valid apabila pertanyaan dalam kuesioner mampu mengungkap sesuatu yang akan diukur oleh kuesioner tersebut. Pengujian validitas instrument dalam penelitian ini akan menggunakan computer dengan paket program SPSS for windows.

Dipakainya instrument yang reliabel didalam mengumpulkan data, untuk harapan hasil penelitian dapat jadi reliabel pula. Instrument yang reliabel adalah syarat mutlak agar memperoleh hasil penelitian reliabel. Sesudah diketahuinya validitas juga reliabilitas instrument penelitian, jadi akan dilanjutkan dengan 
I Gede Yudika Putra, Peran Komitmen Organisasional...

dilakukannya analisis data. Dalam penelitian ini, untuk menguji reliabilitas data digunakan teknik analisis formula Alpha Cronbach dengan bantuan computer. Besaran sebuah instrument disimpukan reliabel apabila nilai Alpha Cronbach $\geq$ 0,6. Proses uji reliabilitas instrument didalam penelitian berikut pula dapat dilaksanakan dengan memakai komputer dengan program SPSS for Windows.

Model regresi disebut model yang bagus bila model itu terbebas daripada asumsi klasik statistik. Sebuah model dengan teoritis dapat memberi hasil nilai parameter penduga yang cocok apabila lolos dari syarat asumsi klasik regresi, yang termasuk uji normalitas, multikolineritas, juga heteroskedastisitas. Teknik analisa faktor konfirmatori ataupun Confirmatory Factor Analysis (CFA) adalah model deskripsi mempunyai tujuan agar mendeskriptifkan suatu keadaan ataupun suatu konsep ataupun suatu faktor dengan analisa yang didapatkan itu digunakan untuk measurement model dikarenakan model berikut dipakai dalam menghitung seberapa kuat struktur daripada dimensi yang terbentuk suatu faktor. Analisa faktor dipakai agar memberi penentuan apakah sekelompok variabel bisa direduksi menjadi beberapa faktor saja. Analisis faktor akan mereduksi atau mengelompokkan indikator variabel yang memenuhi persyaratan konsistensi jawaban responden dengan tingkat reliabilitas data yang memadai untuk mencari faktor utama atau dominan. Pada prinsipnya analisis faktor digunakan untuk mengkonfirmasi teori atau konsep apakah indikator terukur mampu menjelaskan variabel yang dibentuk. Model CFA dari masing-masing variabel penelitian, stres kerja (X), komitmen organisasional (M) dan turnover intention (Y). 
Dalam penelitian ini teknik analisis yang digunakan adalah teknik analisis jalur (path analysis). Analisis jalur digunakan untuk menentukan hubungan antara tiga variabel atau lebih dalam mengkonfirmasi ataupun menolak hipotesis. Pondasi penilaian koefisien jalur yaitu analisis korelasi serta regresi juga didalam penilaian memakai perangkat lunak menggunakan program SPSS for windows. Analisis jalur digunakan sebagai menerangkan akibat langsung dan tidak langsung seperangkat variabel bebas dengan seperangkat variabel terikat. Langkah-langkah dalam menguji hipotesis penelitian yang telah disusun dengan menggunakan path analysis menurut Riduwan dan Kuncoro (2011:152) adalah sebagai berikut. 1) Tahap pertama dalam analisis jalur ini adalah menentukan hipotesis dan persamaan strukturalnya. 2) Pada tahap kedua ini adalah meregresikan setiap persamaan struktual antara variabel eksogen (bebas) dengan variabel endogennya (terikat) untuk mengetahui hubungan antara variabel tersebut. 3) Pada tahap ketiga ini adalah menghitung koefisien jalur secara simultan (keseluruhan), 4) Meringkas dan menyimpulkan tahap terakhir yaitu meringkas hasil koefisien jalur dan memberikan interprestasi dari hasil analisis.

Uji Sobel dilakukan untuk menguji peran mediasi yang diberikan oleh variabel komitmen organisasional, maka pengujian signifikan variabel mediasi dalam model dapat diperiksa dari hasil uji pengaruh tidak langsung. Dari pengujian ini dapat di teliti tingkat intervensi dari variabel mediasi apakah memediasi penuh (full mediation) atau memediasi sebagian (partial mediation) atau bukan mediasi. Apabila nilai kalkulasi Z lebih besar dari 1,96 (dengan tingkat kepercayaan 95 persen), maka variabel mediator dinilai secara signifikan 
memediasi hubungan antara variabel terkait dan variabel bebas (Preacher dan Hayes, 2004). Uji sobel dihitung dengan rumus dibawah ini:

$$
Z=\frac{a b}{\sqrt{b^{2} s_{a}^{2}+a^{2} s_{b}^{2}+s_{a}^{2} s_{b}^{2}}}
$$

Keterangan:

$Z=$ nilai kalkulasi sobel

$\mathrm{a}=$ koefisien regresi dari variabel independen $(\mathrm{X})$ terhadap variabel moderator $\left(\mathrm{Y}_{1}\right)$.

$\mathrm{S}_{\mathrm{a}}=$ standar error dari $\mathrm{a}$.

$\mathrm{b}=$ koefisien regesi dari variabel moderator $\left(\mathrm{Y}_{1}\right)$ terhadap variabel dependen $\left(\mathrm{Y}_{2}\right)$

$\mathrm{S}_{\mathrm{b}}=$ standar error dari $\mathrm{b}$.

\section{HASIL DAN PEMBAHASAN}

Karakteristik responden pada penelitian Peran Komitmen Organisaional dalam Memediasi Pengaruh Stres Kerja Terhadap Turnover Intention di PT. Bali Rochmat Jaya yang beralamat di Jalan By. Pass Ir. Soekarno Kediri - Pesiapan, Tabanan, dapat dilihat dari beberapa kriteria yaitu : Umur, Jenis Kelamin, dan Pendidikan Terakhir, berikut disajikan karakteristik responden dari berbagai kriteria tersebut. Berdasar pada umur responden bias didapatkan bahwasannya banyaknya responden yang berumur 21-25 sebesar 10 orang, banyaknya responden yang berumur 26-30 sejumlah 8 orang, banyaknya responden yang memiliki umur 31-35 sejumlah 7 orang, banyaknya responden yang memiliki umur 36-40 sejumlah 6 orang, banyaknya responden yang memiliki umur 40-45 sejumlah 4 orang, banyaknya responden yang memiliki umur 45-49 sejumlah 4 orang serta banyaknya responden yang memiliki umur $>50$ sejumlah 1 orang. Jumlah reponden memiliki jenis kelamin laki-laki sejumlah 30 orang serta jumlah 
responden berkelamin perempuan sebanyak 10 orang. jumlah reponden memiliki jenis kelamin laki-laki sebanyak 30 orang serta jumlah responden memiliki kelamin perempuan sebanyak 10 orang. Tingkat Pendidikan dengan jumlah paling tinggi terdapat di tingkat Pendidikan D3 yang mempunyai jumlah 12 orang, sedangkan pada jumlah yang paling rendah terletak pada tingkat Pendidikan D2 yang berjumlah 4 orang.

Uji validitas bertujuan untuk memeriksa apakah kuesioner sebagai instrumen penelitian sudah tepat untuk mengukur indikator dalam penelitian. Hasil uji validitas menampilkan bahwasannya semua variable mempunyai nilai koefisien korelasi dengan total semua item pernyataan melebihi 0,30 . Hal berikut memberi petunjuk bahwasannya butir-butir pernyataan didalam instrumen penelitian itu valid. Sebuah variabel dinyatakan reliabel bila memberikan nilai Cronbach alpha $(\alpha)>0,60$. Hasil uji reliabilitas memberi petunjuk bahwasannya seluruh variabel mempunyai nilai koefisien Alpha Cronbach melebihi 0,60. Hal ini dapat dikatakan bahwa seluruh variabel didalam penelitian ini yaitu reliabel.

Untuk melakukan pengujian apa data yang dipakai normal ataupun tidak bisa dilaksanakan dengan memakai uji Kolmogorov Smirnov. Bila koefisien Asymp. Sig. (2-tailed) melebihi 0,05 maka data itu terbilang memiliki distribusi normal. Diketahui hasil nilai Kolmogorov Smirnov (K-S) sebanyak 0,405, sedangkan nilai Asymp. Sig. (2-tailed) sebanyak 0,997. Hasil itu memiliki indikasi bahwasannya model persamaan regresi itu memiliki distribusi normal dikarenakan nilai Asymp. Sig. (2-tailed) 0,237 melebihi nilai alpha 0,05. 
I Gede Yudika Putra, Peran Komitmen Organisasional...

Ada tidaknya multikolinearitas bisa terlihat dari nilai tolerance ataupun variance inflation factor (VIF). Bila nilai tolerance melebihi $10 \%$ ataupun VIF Kurang dari 10, jadi dikatakan tak adanya multikolinearitas. Nilai tolerance lebih besar dari $10 \%$ dan nilai VIF lebih kecil dari 10 yang berarti model persamaan regresi 1 bebas dari multikolinearitas. Nilai tolerance untuk setiap variabel lebih besar dari $10 \%$ dan nilai VIF lebih kecil dari 10 yang berarti model persamaan regresi 2 bebas dari multikolinearitas. nilai Sig. dari variabel Stress Kerja serta Komitmen Organisasi masing-masing sebanyak 0,187 juga 0,071. Nilai itu melebihi 0,05 yang mempunyai arti tak adanya pengaruh diantara variabel bebas pada absolute residual. Dengan demikian, model yang dibuat tak mengandung gejala heteroskedastisitas.

Sebelum analisis jalur terlebih dahulu dilakukan analisis faktor konfirmatori untuk mengetahui apakah indikator-indikator tiap variabel dapat mengkonfirmasikan konstruk atau variabel. Analisis faktor dianggap layak jika besaran KMO memiliki nilai minimal 0,5. Semua variabel memiliki nilai KMO > 0,5 , nilai signifikansi $<0,05$ dan nilai chi-square masing-masing 72,554; 87,003; dan 78,192 . Hasil tersebut memberi kesimpulan bahwasannya masing-masing variabel mempunyai kecukupan sample agar analisis faktor. Besaran MSA masing-masing variable lebih tinggi daripada 0,5. Hasil tersebut memiliki arti tiap-tiap model layak dipakai didalam analisis faktor. Besaran Percentage of Variance tiap-tiap variable telah melebihi 60 persen. Hasil tersebut memiliki arti faktor daripada tiap-tiap variable mempunyai rasa layak dalam memberi penjelasan variable faktornya. 
Hasil analisis faktor konfirmatori dari variable Stress Kerja, Komitmen Organisasi dan Turnover Intention memberi petunjuk semua indikator konstruk tersebut mempunyai loading faktor dengan nilai diatas 0,5. Semua variabel memiliki loading factor di atas 0,50 atau factor loading yang tinggi. Dengan hasil ini, maka dapat dikatakan indikator-indikator pembentuk variabel Stress Kerja, Komitmen Organisasi dan Turnover Intention telah menunjukkan sebagai indikator yang kuat. Selanjutnya berdasar analisis faktor konfirmatori ini, maka model penelitian bisa dipakai untuk analisis selanjutnya tanpa dimodifikasi atau penyesuaian-penyesuaian.

Tahapan melaksanakan teknik analisis jalur adalah: 1) Merancang model analisis jalur secara teoritis. Model tersebut juga dapat dinyatakan dalam bentuk persamaan. 2) Perhitungan koefisien path dilakukan dengan analisis regresi melalui software SPSS 18.0 for Windows, diperoleh hasil yang ditunjukan pada Tabel 1 berikut.

Tabel 1.

Hasil Analisis Jalur Struktur 1

\begin{tabular}{lcrr}
\hline \multicolumn{1}{c}{ Variabel } & Koefisien Regresi & t & Signifikansi \\
\hline \multicolumn{1}{c}{ Stress Kerja } & $-0,642$ & $-5,724$ & 0 \\
\hline F Hitung & & $\mathbf{3 2 , 7 6 8}$ \\
Signifikansi & $\mathbf{0}$ \\
R $_{1}$ & $\mathbf{0 , 4 6 3}$ \\
Adjusted R Square & $\mathbf{0 , 4 4 9}$ \\
\hline Sumber: Data Diob, 2017 &
\end{tabular}

Sumber: Data Diolah, 2017

Hasil analisis jalur substruktur 1 seperti yang disajikan pada Tabel 1, maka persamaan strukturalnya adalah sebagai berikut. 


$$
\begin{aligned}
& \mathrm{M}=\beta 1 \mathrm{X}+\mathrm{e}_{1} \ldots \ldots \ldots \\
& \mathrm{M}=-0,642 \mathrm{X}+\mathrm{e}_{1}
\end{aligned}
$$

Tabel 2.

Hasil Analisis Jalur Struktur 2

\begin{tabular}{lcrr}
\hline \multicolumn{1}{c}{ Variabel } & Koefisien Regresi & t & \multicolumn{1}{c}{ Signifikansi } \\
\hline Stress Kerja & 0,338 & 2,641 & 0,012 \\
& & & \\
Komitmen organisasional & $-0,505$ & $-3,72$ & 0,001 \\
& & & $\mathbf{3 1 , 8 3 2}$ \\
\hline F Hitung & & $\mathbf{0}$ \\
Signifikansi & & $\mathbf{0 , 6 3 2}$ \\
R2 & & $\mathbf{0 , 6 1 3}$ \\
Adjusted R2 Square & & \\
\hline
\end{tabular}

Sumber: Data Diolah, 2017

Hasil analisis jalur substruktur 2 seperti yang disajikan pada Tabel 4.20, maka persamaan strukturalnya adalah sebagai berikut.

$$
\begin{aligned}
& Y=\beta 2 X+\beta 3 M+e_{2} \ldots \ldots \ldots \\
& Y=0,338 X-0,505 M+e_{2}
\end{aligned}
$$

Berdasar model substruktur 1 juga substruktur 2, maka bias tersusun model diagram jalur akhir. Sebelum menyusun model diagram jalur akhir, lebih dulu dihitung nilai standar eror. Berdasar penilaian pengaruh error (Pei), diperoleh hasil pengaruh error $\left(\mathrm{Pe}_{1}\right)$ sebanyak 0,732 juga pengaruh error $\left(\mathrm{Pe}_{2}\right)$ sebesar 0,606. Hasil koefisien determinasi total adalah sebagai berikut.

$$
\begin{aligned}
\mathrm{R}^{2} \mathrm{~m} & =1-\left(\mathrm{Pe}_{1}\right)^{2}\left(\mathrm{Pe}_{2}\right)^{2} \\
& =1-(0,732)^{2}(0,606)^{2} \\
& =1-(0,535)(0,367) \\
& =1-0,196=0,804
\end{aligned}
$$


Nilai determinasi total sebesar 0,804 memiliki arti bahwasannya sebesar 80,4\% variasi Turnover Intention dipengaruhi oleh variasi Stress Kerja dan Komitmen organisasional, sedangkan sisa sebesar 19,6\% djelaskan oleh faktor lain yang tak masuk kedalam model. Berdasar hasil analisis pengaruh Stress Kerja terhadap Komitmen organisasional diperoleh nilai Sig. $\mathrm{t}$ sebesar 0,000 dengan nilai koefisien beta $-0,642$ Nilai Sig. $\mathrm{t} 0,000<0,05$ memiliki indikasi bahwasannya $\mathrm{H}_{0}$ ditolak dan $\mathrm{H}_{1}$ diterima. Hasil ini memiliki arti bahwa Stress Kerja berpengaruh negatif terhadap Komitmen organisasional.

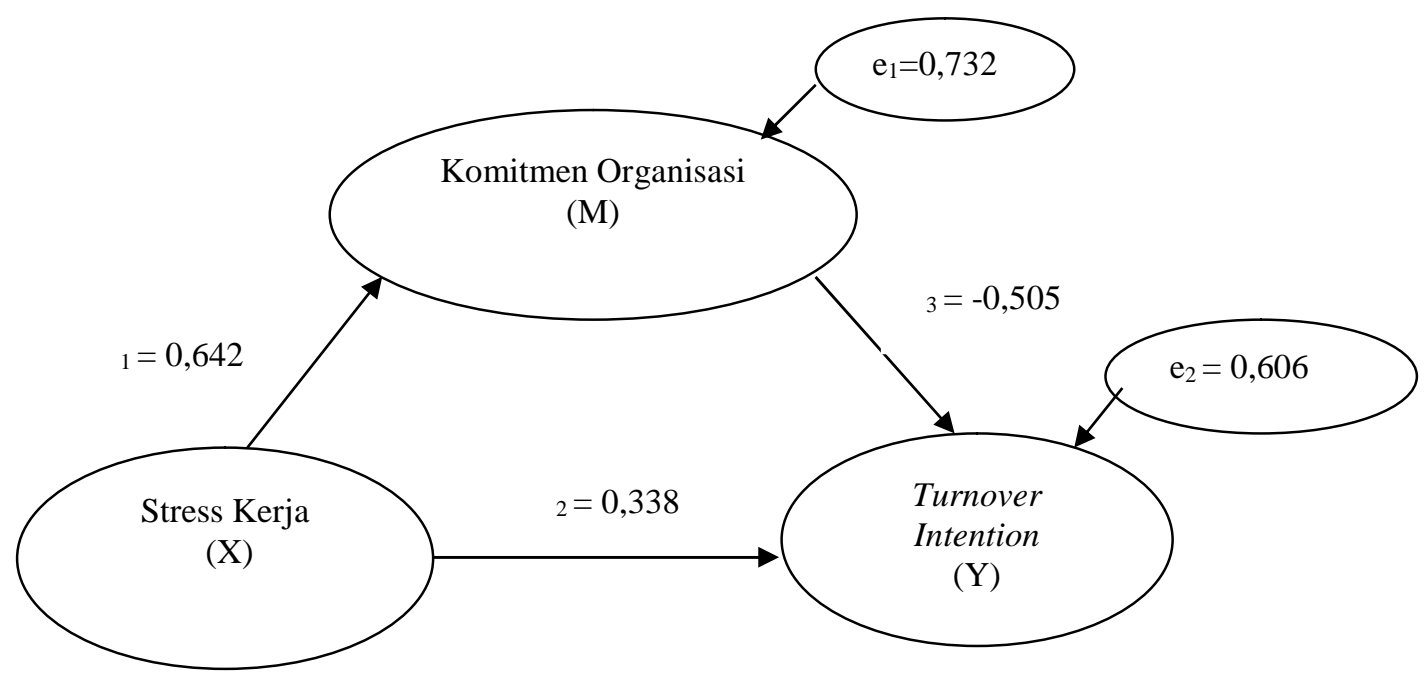

\section{Gambar 2. Validasi Model Diagram Jalur Akhir}

Sumber: Data Diolah, 2017

Berdasarkan hasil analisis pengaruh Stress Kerja terhadap Turnover Intention didapatkan nilai Sig. t sebesar 0,012 dengan nilai koefisien beta 0,338. Nilai Sig. t 0,012 <0,05 mengindikasikan bahwasannya $\mathrm{H}_{0}$ ditolak dan $\mathrm{H}_{1}$ diterima. Hasil ini memiliki arti bahwasannya stress kerja berpengaruh positif terhadap turnover intention. Berdasarkan hasil analisis pengaruh komitmen organisasional terhadap turnover intention diperoleh nilai Sig. $\mathrm{t}$ sebesar 0,001 dengan nilai koefisien beta $-0,505$. Nilai Sig. t $0,001<0,05$ mengindikasikan 
I Gede Yudika Putra, Peran Komitmen Organisasional...

bahwa $\mathrm{H}_{0}$ ditolak dan $\mathrm{H}_{1}$ diterima. Hasil ini memiliki arti bahwasannya komitmen oragnisasi berpengaruh negatif terhadap turnover intention. Hasil koefisien jalur pada hipotesis penelitian dapat digambarkan pada Gambar 2.

Berdasar diagram jalur pada Gambar 2, maka bisa dihitung besar tidaknya pengaruh langsung dan pengaruh tidak langsung serta pengaruh total antar variabel. Perhitungan pengaruh antar variabel dirangkum dalam Tabel 3 berikut.

Tabel 3.

Pengaruh Langsung dan Pengaruh Tidak Langsung serta Pengaruh Total Antar Variabel

\begin{tabular}{lcccc}
\hline $\begin{array}{c}\text { Pengaruh } \\
\text { Variabel }\end{array}$ & $\begin{array}{c}\text { Pengaruh } \\
\text { Langsung }\end{array}$ & $\begin{array}{c}\text { Pengaruh Tidak Langsung Melalui } \\
\text { Komitmen organisasional (M) }(\boldsymbol{\beta 1} \mathbf{x} \boldsymbol{\beta 3})\end{array}$ & $\begin{array}{c}\text { Pengaruh } \\
\text { Total }\end{array}$ \\
\hline $\boldsymbol{\beta}_{1}$ & $\mathrm{X} \rightarrow \mathrm{M}$ & 0,642 & - & 0,642 \\
$\boldsymbol{\beta}_{2}$ & $\mathrm{X} \rightarrow \mathrm{Y}$ & 0,338 & 0,137 & 0,485 \\
$\frac{\beta}{3}$ & $\mathrm{M} \rightarrow \mathrm{Y}$ & $-0,505$ & - & $-0,505$ \\
\hline Sumber: & Data Diolah, 2017 & &
\end{tabular}

Uji keterandalan model ataupun uji kelayakan model ataupun yang lebih populer disebut sebagai uji $\mathrm{F}$ (ada juga yang menyebutnya sebagai uji simultan model) merupakan tahapan awal mengidentifikasi model regresi yang diestimasi layak atau tidak. Sig. Tabel ANOVA memberi petunjuk besar angka probabilitas ataupun signifikansi pada hitungan ANOVA. Nilai yang tertera dipakai untuk uji kelayanan Model Analisis (dimana sejumlah variabel x memberikan pengaruh variabel y) dengan ketentuan angka probabilitas yang baik untuk dipakai sebagai model regresi harus $<0,05$. Nilai ini bisa dilihat pada kolom Sig. Jika Sig. $<0,05$, maka Model Analisis dianggap layak. Jika Sig. > 0,05, maka Model Analisis dianggap tidak layak. 
Tabel 4.

Hasil Uji ANOVA Struktur 1

\begin{tabular}{|c|c|c|c|c|c|c|}
\hline & Model & Sum of Squares & Df & Mean Square & $\mathbf{F}$ & Sig. \\
\hline \multirow{3}{*}{1} & Regression & 145.102 & 1 & 145.102 & 32.768 & $.000^{\mathrm{a}}$ \\
\hline & Residual & 168.273 & 38 & 4.428 & & \\
\hline & Total & 313.375 & 39 & & & \\
\hline
\end{tabular}

Sumber: Data Diolah, 2017

Tabel 4 hasil uji ANOVA struktur 1 (UJI F) di atas, diperoleh nilai kelompok pembanding $=1$, nilai dalam kelompok penyebut $=39$, pada alpha $=0,05$ maka nilai $\mathrm{F}$ tabelnya adalah F0,05 $(1,39)=4,09$. Sedang $F_{\text {hitung }}=32,768$. Nilai $F_{\text {hitung }}>F_{\text {tabel }}, 32,768>4,09$, dengan nilai sig. $0,000<0,05$. Maka $\mathrm{H}_{0}$ ditolak pada taraf nyata $0,05\left(\mathrm{H}_{1}\right.$ diterima). Kesimpulannya, pada kelompok yang diuji memiliki perbedaan yang nyata (signifikan), sehingga dapat dikatakan bahwa stress kerja berpengaruh secara simultan terhadap turnover intention.

Tabel 5.

Hasil Uji ANOVA Struktur 2

\begin{tabular}{llccccc}
\hline \multicolumn{1}{c}{ Model } & Sum of Squares & Df & Mean Square & F & Sig. \\
\hline $1 \quad$ Regression & 145.102 & 1 & 145.102 & 32.768 & $.000^{\mathrm{a}}$ \\
& Residual & 168.273 & 38 & 4.428 & & \\
$\quad$ Total & 313.375 & 39 & & & \\
\hline \multicolumn{2}{l}{ Sumber: Data Diolah, 2017} & & & &
\end{tabular}

Tabel 5 hasil uji anova struktur 2 (UJI F) di atas, didapatkan nilai kelompok pembanding $=2$, nilai didalam kelompok penyebut $=39$, pada alfa $=0,05$ maka nilai $F$ tabelnya adalah F0,05(2,39) $=3,24$. Sedang $F_{\text {hitung }}=31,832$. Nilai $F_{\text {hitung }}>$ $\mathrm{F}_{\text {tabel, }} 31,832>3,24$, dengan nilai sig. $0,000<0,05$. Maka $\mathrm{H}_{0}$ ditolak pada taraf nyata $0,05\left(\mathrm{H}_{1}\right.$ diterima). Kesimpulannya, di kelompok yang diuji mempunyai perbedaan yang nyata (signifikan), sehingga dapat dikatakan bahwa Stress Kerja, dan Komitmen Oragnisasi berpengaruh secara simultan terhadap Turnover 
I Gede Yudika Putra, Peran Komitmen Organisasional...

Intention. Hasil Uji Sobel menunjukkan bahwa hasil tabulasi $\mathrm{Z}=3,141>1,96$ dengan tingkat signifikansi $0,001<0,05$ yang berarti variabel mediator yakni Komitmen organisasional dinilai secara signifikan memediasi hubungan antara Stress Kerja terhadap Turnover Intention.

Tujuan dari penelitian ini salah satunya adalah untuk menjelaskan pengaruh stress kerja terhadap komitmen organisasional. Berdasarkan hasil analisis pengaruh stress kerja terhadap komitmen organisasional diperoleh nilai Sig. t sebesar 0,000 dengan nilai koefisien beta sebesar $-0,642$. Nilai Sig. t $0,000<0,05$ mengindikasikan bahwa $\mathrm{H}_{0}$ ditolak dan $\mathrm{H}_{1}$ diterima. Hasil ini mempunyai arti bahwa stress kerja berpengaruh negatif terhadap komitmen oragnisasi. Hal ini menunjukkan bahwa semakin tinggi stress kerja maka semakin rendah komitmen organisasional.

Berdasarkan hasil analisis pengaruh stress kerja terhadap turnover intention diperoleh nilai Sig. $\mathrm{t}$ sebesar 0,012 dengan nilai koefisien beta 0,338. Nilai Sig. $\mathrm{t}$ $0,012<0,05$ mengindikasikan bahwa $\mathrm{H}_{0}$ ditolak dan $\mathrm{H}_{1}$ diterima. Hasil ini mempunyai arti bahwa stress kerja berpengaruh positif terhadap turnover intention. Apabila stress kerja pegawai semakin tinggi, maka turnover intention pegawai akan semakin tinggi pula. Berdasarkan hasil analisis pengaruh Komitmen organisasional terhadap turnover intention diperoleh nilai Sig. $\mathrm{t}$ sebesar 0,001 dengan nilai koefisien beta $-0,505$. Nilai Sig. t 0,001 $<0,05$ mengindikasikan bahwa $\mathrm{H}_{0}$ ditolak dan $\mathrm{H}_{1}$ diterima. Hasil ini mempunyai arti bahwa komitmen organisasional berpengaruh negatif terhadap turnover intention. Apabila komitmen organisasional pegawai semakin tinggi, maka turnover intention akan semakin rendah. 
Berdasarkan hasil Uji Sobel pada Tabel menunjukkan bahwa hasil tabulasi Z = $3.1415>1,96$ dengan tingkat signifikansi $0,001<0,05$ yang berarti variabel mediator yakni komitmen organisasional dinilai secara signifikan memediasi hubungan antara stress kerja terhadap Turnover Intention. Apabila tingkat komitmen organisasional tinggi, maka stress kerja akan semakin rendah dan berujung pada menurunnya turnover intention. Untuk pegawai serta organisasi, implikasinya didalam penelitian berikut didalam melaksanakan kegiatan organisasi yaitu terlibatnya pemimpin sangatlah penting, hingga organisasi bisa melaksanakan aktivitas yang bisa menolong agar terbentuk kerjasama yang bagus diantara pemimpin organisasi serta pegawai jadinya tujuan organisasi bisa dicapai sesuai dengan yang menjadi harapan. Komitmen organisasional berpengaruh negatif terhadap turnover intention. Komitmen organisasional adalah salah satu faktor terbentuknya tingkah laku, yang di dalam penelitian ini adalah proses terbentuknya tingkah laku turnover intention. Bagi pegawai serta organisasi implikasi penelitiannya yaitu organisasi haruslah bisa memberi peningkatan cara kerja organisasi hingga komitmen afektif yang dipunyai pegawai pada organisasi juga bisa menjadi lebih baik lagi.

\section{SIMPULAN DAN SARAN}

Simpulan dari penelitian ini, berdasarkan hasil analisis dan pembahasan sebelumnya adalah sebagai berikut. 1) Stres kerja berpengaruh negatif signifikan terhadap komitmen organisasi. Stres kerja yang tinggi menyebabkan penurunan komitmen organisasi, yang berarti apabila seorang pekerja mengalami stress dalam bekerja, maka komitmen organisasional dari pekerja tersebut akan 
I Gede Yudika Putra, Peran Komitmen Organisasional...

menurun. 2) Stress kerja berpengaruh positif signifikan terhadap turnover intention. Stress kerja yang tinggi dapat meningkatkan turnover intention, yang berarti apabila seorang pekerja mengalami stress dalam bekerja, maka tingkat turnover intention yang dimiliki pekerja tersebut akan meningkat. 3) Komitmen organisasi berpengaruh negatif terhadap turnover intention. Komitmen organisasional yang tinggi dapat menurunkan turnover intention, turnover intention, yang berarti apabila komitmen organisasional yang dimiliki pekerja tinggi, maka dapat menurunkan turnover intention yang dimiliki pekerja tersebut. 4) Komitmen organisasi terbukti memediasi pengaruh antara stress kerja dengan turnover intention secara parsial.

Saran dari penelitian ini, berdasarkan hasil analisis dan pembahasan sebelumnya adalah sebagai berikut. Hasil penelitian menunjukan bahwa stress kerja yang tinggi dapat menurunkan komitmen organisasional bagi pekerja, hal ini dapat menyebabkan pekerja yang mengalami stress dalam bekerja akan mengabaikan komitmen dari organisasi PT Bali Rochmat Jaya. Apabila komitmen organisasional menurun, maka dapat menyebabkan menurunnya kinerja dari organisasi PT Bali Rochmat Jaya. Kemudian stres kerja yang tinggi dapat meningkatkan turnover intention, stres kerja yang tinggi akan menyebabkan pekerja berpikir untuk keluar atau mengganti pekerjaannya. Hendaknya PT Bali Rochmat Jaya memberikan motivasi positif kepada karyawannya yang dianggap mengalami stress sehingga dapat menurunkan tingkat stress kerja, adapun cara agar stres kerja tidak timbul yaitu dengan cara mengadakan acara rutin dengan anggota kantor yang bersifat kekeluargaan seperti rekreasi bersama anggota 
kantor, outbound dan lain sebagainya tujuannya agar dapat mempererat hubungan antar karyawan dan meningkatkan komitmen organisasional.

Saran yang dapat diberikan kepada peneliti selanjutnya yaitu mengembangkan variabel-variabel penelitian yang lainnya agar tidak terjadi perbedaan persepsi antara peneliti dengan responden. Selain itu berdasarkan hasil koefisien determinasi total, ditemukan bahwa variable bebas dan mediator mampu menjelaskan variable turnover intention sebesar 80,4 persen sedangkan sisanya sebesar 19,6 persen dijelaskan oleh faktor lain diluar model penelitian. Peneliti selanjutnya dapat menggunakan variable lain seperti kepuasan kerja, motivasi, dan gaji dan lain-lain.

\section{REFERENSI}

Ahmed, Ishfaq, Wan Khairuzzaman Wan Ismail, Salmiah Mohamad Amin and Muhammad Ramzan. 2013. Influence of Relationship of POS, LMX and Organizational Commitment On Turnover intention. Organization Development Journal, 31(1): pp: 55-68.

Alves, Marcia Guimaraes De Mello. Dora Chor. Eduardo Faerstein. Claudia de S. Lopes. 2004. Short version of "job stress scale": a portuguase-language adaption. Rev Saude Publica. Vol. 38. No. 2. pp : 1-7.

Anatan, Lina dan Ellitan, Lena. 2007. Manajemen Sumber Daya Manusia Dalam Bisnis Modern. Bandung: Alfabeta.

Aydogdu, S. and Asikgil, B. 2011. An Empirical Study of the Relationship Among Job Satisfaction, Organizational Commitment and Turnover intention. International Review of Management and Marketing, 1(3): pp: 43-53.

Cha, Jae Min., Kim Seung Hyun., Cichy, Ronald F. 2011. Job Satisfaction, Organizational Commitment, and Contexual Performance: Examining Effects of Work Status and Emotional Intelligence among Private Club Staff Members. Psychology \& Marketing, 21(6): pp: 405-424.

Dockel, Andreas. 2006. The effect of retention factors on organizational commitment: an investigation of high technology employee. SA Journal of Human Resource Management. Vol. 4. No. 28. pp: 20-2 
Firth, Lucy, Mellor, David J, Moore, Kathleen A, Loquet, Claude. 2004. How can Managers Reduce Employee Intention to quit? Journal of Managerial Psychology. Vol. 19, No. 2, pp. 170-187.

Hermitha. 2011. Pengaruh Stres kerja terhadap Kinerja Karyawan pada PT. Semen Tonasa (PERSERO) pangkep. Skripsi. Makasar: Universitas Hasanuddin.

Handaru, Agung Wahyu, Nailul Muna. 2012. Pengaruh Kepuasan Gaji dan Komitmen Organisasi terhadap Intensi Turnover pada Divisi PT. Jamsostek. Jurnal Riset Manajemen Sains Indonesia (JRMSI). 3(1): h: 119.

Hlatywayo, C. K..Mlanga, T.S. \&Zingwe, T. 2014. Precursors of emotional stability, stress and work-family conflict among female bank employees. International Business \& Economics Research Journal. Vol. 13. No. 4.pp :861-866.

Irwanto, I Gede Riana dan Ni Nyoman Kerti Yasa. 2016. Peran Komitmen Organisasional Memediasi Pengaruh Stres Kerja Dan Kepuasan Kerja Terhadap Intensi Keluar. E-Jurnal Ekonomi dan Bisnis Universitas Udayana. 5 (9): pp: 2891-2910.

Klassen, Robert M. 2011. The Occupational Commitmen and Intention to Quit of Praticing and Pre-service Teacher: Influence of Self-Efficacy, Job stres and Teaching Context. Contemporary educational psychology. Vol.36 (2), pp: 114-129.

Khatibi, A. H. Asadi and M. Hamidi. 2009. The Relationship Between Job Stress and Organizational Commitment in National Olympic and Paralympic Academy. World Journal of Sport Science, 2(4): pp: 272-278.

Kumar, R., Ramendran, C., \& Yacob, P. 2012. A Study on Turnover intentionin Fast Food Industry: Employees' Fit to the Organizational Culture and the Important of their Commitment. International Journal of Academic Research in Business and Social Sciences, 2(5): pp: 9-42.

Layne, C., Hohenshill, T., Singh, K. 2004. The Relationship of Occupational Stres, Psychological Strain, and Coping Resources to the Turnover intention of Rehabilitation Counselors. Rehabilitation Counseling Bulletin. Vol. 48, No. 1, pp: 19-29.

Meyer, John P. Herscovith L. 2001. Commitment in the workplace : toward general model. Human Resource Management Review. Vol. 11. pp: 299326. 
Meyer, John P. Natalie J. Allen. 1991. A three-component conceptualization of organizational commitment. Human Resource Management Review. Vol. 1. No.1. pp. 61-89.

Mitchell, Ojmaarh., Mackenzie, Doris Layton., Styve, Gaylene. J., Gover, Angela. 2014. The Impact of Individual, Organizational and Environmental Attributes on Voluntary Turnover Among Juvenile Correctional Staf Members. Justice Quarterly: Academy of Criminal Justice Science. Vol. 17, No. 2, pp: 332-357.

Novriyadhi, R. O., dan Gede. R. 2015. Keadilan Organisasional Terhadap Kepuasan Keja Dan Komitmen Organisasi Pada PT Astra International Auto 2000 Denpasar. Jurnal Manajemen Unud. 4(6): h: 1753-1770.

Preacher, K. J., \& Hayes, A. F. 2004. SPSS and SAS procedures for estimating indirect effects insimple mediation models. Behavior Research Methods, Instruments, and Computers. 36, pp: 717-731.

Pool, S . W. 2000. Organizational Culture and its relationship between Job Tension in measuring outcomes Among Business Executive. The Journal Of Management Development. Vol 19. No. 1. pp: 32-49.

Parvaiz, L., Saba B., Ambar K., and Yasir A.F. 2015. Impact Of Stressors (Role Conflict, Role overload, Leadership Support and Organizational Politics) on Job Stress and its Subsequent Impact on Turnover intention. International Journal of Business and Management Invention. 4(10), pp: 52-63.

Qureshi, M. I. 2013. Relationship Between Job Stress, Workload, Environment and Employees Turnover intention: What We Know, What Should We Know. World Applied Sciences Journal, 23(6): pp: 764-770.

Qureshi, M.I., Jamil, R. A., Iftikhar, M., Arif, S., Lodhi, S., Naseem, I., and Zaman, K. 2012. Job Stres, Workload, Environment and Employees Turnover Intentions: Destiny or Choice. Jurnal of Management Info, 65(8), pp: 230-241.

Riduwan dan Kuncoro, Engkos Achmad. 2011. Cara menggunakan dan Memakai Path Analysis (Analisis Jalur). Cetakan Keempat. Bandung: ALFABETA

Riduwan dan Sunarto. 2012. Pengantar Statistika Untuk Penelitian Pendidikan, Sosial, Ekonomi dan Bisnis. Bandung: Alfabeta.

Setiawan, I Nyoman Agus. 2016. Pengaruh Job Insecurity Terhadap Kepuasan Kerja Dan Turnover Intention Pada Karyawan Legian Village Hotel. EJurnal Manajemen Unud, 5(8), h: 4983-5012 
Saqib, M. K., Kundi, G. M., Shadiullah, K., Irfanullah, K., Hamid, K., and Naseem, B. Y. 2014. The Cause-\& Effect and Correlation between Job Satisfaction and Organizational commitment on Intention to leave among the Academicians in higher Educational Institutions of Khyber Pakhtunkhwa, Pakistan. International Journal of Academic Research in Business and Social Sciences. 4(2), pp: 2222-6990.

Sianipar, Anggie Rumondang Berliana dan Kristiana Haryanti. 2014. Hubungan Komitmen Organisasi dan Kepuasan Kerja Dengan Intensi Turnover Pada Karyawan Bidang Produksi CV.X. Psikodimensia, 13(1), h: 98-114.

Sugiyono. 2013. Metode Penelitian Bisnis. Bandung : Alfabeta

Suryani, Ratna. 2011. Analisis Pengaruh Persepsi Dukungan Organisasi terhadap Turnover intentions dengan Peran Komitmen Keorganisasian sebagai Mediasi. Tesis. Jakarta: Fakultas Ilmu Sosial Politik Departemen Ilmu Administrasi Program Pasca Sarjana Universitas Indonesia.

Velnampy, T and Aravinthan. S. A. 2013. Occupational stress and organizational commitment in private banks: a srilankan experience. European Journal of Business and Management. Vol.5. No.7. pp: 78-99

Wan, Li Kuean., Edward Wong Sek Khin and Sharon Kaur. 2010. Employees' Turnover intention to Leave: The Malaysian Context. The South East Asian Journal Of Management. Vol.IV hal 93-110 